\title{
Transport Properties of Concrete
}

\section{Measurement and Applications}

\author{
Peter A. Claisse
}

The second edition of this book has now been published.

Click here: Synopsis 2nd ed.pdf

Woodhead Publishing is an imprint of Elsevier, 80 High Street, Sawston, Cambridge, CB22 3HJ, UK, 225 Wyman Street, Walthan, MA 02451, USA Langford Lane, Kidlington, OX5 1GB, UK

Library of Congress Control Number: ISBN 978-1-78242-306-5 (print), ISBN 978-1-78242-319-5 (online)

A research monograph published May 2014 order from Amazon order from Elsevier

A review of the book: http://www.claisse.info/My\%20papers/COMA-D-15$\underline{00024 \text { PClaisse.pdf }}$

Synopsis

The transport properties of concrete are measurements of the ability of ions and fluids to move through the material. These properties largely determine the durability of concrete and of steel embedded within it, as well as the effectiveness of structures such as landfill containment barriers. Transport properties of concrete covers how to measure transport properties and how to use the results to model performance.

Chapters 1 and 2 explain in detail what transport properties are and how to write computer models for transport processes. Computer models written in basic code are presented and explained. Chapters 3 to 12 cover a wide range of tests for the transport properties of concrete, and present methods for calculating the values for these properties from the test results using analytical and numerical models. Chapters 13 to 15 then show how the values obtained can be used to predict the durability of reinforced concrete, to model the effect of gas pressure, and to model waste containment structures. A number of practical examples are given in which the calculations and computer models have been applied to real experimental data.

Transport properties of concrete provides a comprehensive examination of the subject, and will be of use to all concerned with the durability and effectiveness of concrete 
structures.

The book explains:

- What the transport properties are and how they move ions and fluids through concrete.

- How to write computer models for the transport processes.

- How to choose a method to measure surface absorption of concrete - and how much of the sample it actually tests.

- How to prepare the concrete surface for testing - particularly if it is wet.

- How water vapour moves during the drying of concrete.

- How porosity affects the transport processes.

- What happens in the concrete if you apply a voltage for rapid testing of chloride migration.

- Why chloride migration generates a voltage in a test even if you don't apply one and why this affects the results.

- How transport properties control the durability of structures.

- How to use transport properties to model waste containment structures.

- How to prepare cracked samples for permeability testing that don't fall apart.

\section{About the Author}

Peter A. Claisse is an emeritus professor at Coventry University and the author of more than 100 publications on construction materials. He graduated with a degree in Physics from Oxford University and then spent the next 9 years working as a Civil Engineer on major UK construction sites including four years on the Torness nuclear power station. He has been at Coventry University for the last 20 years teaching Civil Engineering Materials and researching transport processes in concrete and the use of secondary materials in cement. He is a Fellow of the Institution of Civil Engineers.

By the same author: Civil Engineering Materials 